\title{
Multidecadal variability in local growing season during 1901-2009
}

\author{
Jiangjiang Xia $\cdot$ Zhongwei Yan $\cdot$ Peili Wu
}

Received: 26 March 2012/ Accepted: 26 June 2012/Published online: 18 July 2012

(C) The Author(s) 2012. This article is published with open access at Springerlink.com

\begin{abstract}
Global warming exerts a lengthening effect on the growing season, with observational evidences emerging from different regions over the world. However, the difficulty for a global overview of this effect for the last century arises from limited availability of the long-term daily observations. In this study, we find a good linear relationship between the start (end) date of local growing season (LGS) and the monthly mean temperature in April (October) using the global gridded daily temperature dataset for 1960-1999. Using homogenized daily temperature records from nine stations where the time series go back to the beginning of the twentieth century, we find that the rate of change in the start (end) date of the LGS for per degree warming in April (October) mean temperature keeps nearly constant throughout the time. This enables us to study LGS changes during the last century using global gridded monthly mean temperature data. The results show that during the period 1901-2009, averaged over the observation areas, the LGS length has increased by a rate of 0.89 days decade ${ }^{-1}$, mainly due to an earlier start $\left(-0.58\right.$ days decade $\left.{ }^{-1}\right)$. This is smaller than those estimates for the late half of the twentieth century, because of multidecadal climate variability (MDV). A MDV
\end{abstract}

\footnotetext{
J. Xia $\cdot$ Z. Yan $(\bowtie)$

Key Laboratory of Regional Climate-Environment for East Asia, Institute of Atmospheric Physics, Chinese Academy of Sciences, Beijing 100029, China

e-mail: yzw@tea.ac.cn

J. Xia

Graduate University of Chinese Academy of Sciences,

Beijing 100049, China

P. Wu

Hadley Centre, Met Office, Exeter EX1 3PB, UK
}

component of the LGS index series is extracted by using Ensemble Empirical Mode Decomposition method. The MDV exhibits significant positive correlation with the Atlantic Multi-decadal Oscillation (AMO) over most of the Northern Hemisphere lands, but negative in parts of North America and Western Asia for start date of LGS. These are explained by analyzing differences in atmospheric circulation expressed by sea level pressure departures between the warm and cool phases of AMO. It is suggested that MDV in association with AMO accelerates the lengthening of LGS in Northern Hemisphere by $53 \%$ for the period 1980-2009.

Keywords Global warming - Local growing season · Multidecadal variability $\cdot$ AMO

\section{Introduction}

Growing season length (GSL) exerts a strong control on ecosystem functions (White et al. 1999). It affects both physical and biological systems in an array of ways, dealing with crop productivity (Myneni et al. 1997; Chmielewski et al. 2004; Peng et al. 2004; ACIA 2004), viniculture (Nemani et al. 2001; Jones et al. 2005), forestry (Cayan et al. 2001; Matsumoto et al. 2003), animals (Crick and Sparks 1999; Roy and Sparks 2000; Cotton 2003), and hydrological cycle (Peterson et al. 2002; Groisman et al. 2004; Yang et al. 2002; Barnett et al. 2005). In addition, GSL also influences the carbon storage of the earth system (Goulden et al. 1996; Keeling et al. 1996). A general conclusion is that GSL has increased by 10-20 days in the mid-high latitudes along with a warming trend during the last few decades, mainly due to an earlier onset of the growing season as evidenced in satellite, phenological and 
meteorological observations, as summarized by Linderholm (2006).

A number of regional studies have reported on a late twentieth century lengthening of growing season for most of the Northern Hemisphere (e.g., Cayan et al. 2001; Frich et al. 2002; Parmesan and Yohe 2003; Root et al. 2003; Linderholm et al. 2008; Song et al. 2010). Among these studies, the climatological definitions of growing season indicators with reference to temperature are often used, taking advantage of fine spatial and temporal resolution and the long time series of the meteorological observations. Due to regional differences in climate and ecological characteristics, it is not straightforward to compare changes in growing season on a global scale (Linderholm 2006). For example, the climatological growing season is often defined by using fixed temperature thresholds, like $5{ }^{\circ} \mathrm{C}$ (Jones and Briffa 1995; Carter 1998; Frich et al. 2002), or $0{ }^{\circ} \mathrm{C}$ (Brinkmann 1979; Cooter and LeDuc 1995; Kunkel et al. 2004), which may not be valid at warmer regions. Moreover, there are still discrepancies due to different methods applied even using one fixed temperature threshold (Walther and Linderholm 2006; Qian et al. 2009).

To facilitate regional comparison and to gain a global overview, it is necessary to use the same method for assessing regional changes in growing season. In order to "examine the climatological changes that underline all the impacts of changes in growing season, rather than narrow the scope to a singular aspect of local interest only", Christidis et al. (2007) defined a local growing season (LGS) based on the local annual mean temperature as a threshold. In this way, for most temperate land regions, the start (end) date of the growing season should occur in the middle spring (autumn) phase. This makes available a reasonable comparison of changes in growing season over the world. Their results suggest that global growing season length had increased by about 1.5 days decade ${ }^{-1}$ during the period 1950-1999. Because of the relatively short period the analysis covered, the estimated trends could contain contributions from low-frequency natural climate variability such as the Atlantic Multidecadal Oscillation (AMO), which is considered as a leading near-global pattern of multidecadal variability in surface temperature (Schlesinger and Ramankutty 1994; Knight et al. 2005, 2006; Trenberth and Shea 2006).

Most of currently available and quality-controlled global climate datasets are monthly averages. To make these data usable for studying long-term changes in growing season, it is beneficial to investigate possible relationships between monthly temperatures and growing season indices. In this paper, we will establish a good linear relationship between the start (end) date of LGS and the monthly mean temperature of April (October), by analyzing the quasi-global gridded daily land surface air temperature dataset for the period 1960-1999 produced by Caesar et al. (2006). This linear relationship enables us to define a monthly-temperature-dependent date-shift-rate. The robustness of this date-shift-rate is examined using nine strictly quality-controlled daily temperature series back to the beginning of the twentieth century from Australia, China, Europe, and North America. Using this relationship, the present paper illustrates the changes in LGS during the twentieth century by analyzing the April/October temperature instead, based on the CRU T3.1 monthly temperature dataset (Jones and Harris 2008). The Ensemble Empirical Mode Decomposition (EEMD) method, recently developed for nonlinear and non-stationary time-series analysis (Huang et al. 1998; Huang and Wu 2008; Wu and Huang 2009), is employed to adaptively decompose the time series of the LGS indices in order to extract multidecadal variability component.

The structure of this paper is as follows. Section 2 describes data and methods used in this study. Section 3 presents changes in LGS for the twentieth century and discusses the relationship between multidecadal variability of LGS and AMO. A summary is presented in Sect. 4.

\section{Data and methods}

\subsection{Data}

\subsubsection{Global daily temperature 1960-99}

The quasi-global gridded land dataset of daily maximum and minimum temperatures produced by Caesar et al. (2006) is used to generate a daily mean temperature dataset by simply averaging the maximum and minimum on the same grid and time span. The spatial resolution is $2.5^{\circ}$ latitude by $3.75^{\circ}$ longitude and the period covers 1960-99.

\subsubsection{Nine daily temperature time series 1901-2008}

Three of the long-term daily temperature series for Central England, Shanghai, and Stockholm were homogenized by Parker et al. (1992), Yan et al. (2001), and Moberg et al. (2002), respectively. Eight daily temperature series were chosen from the Global Historical Climatology Network at the National Climatic Data Center (NCDC, Table 1).

All the chosen series in Table 1 satisfy the following conditions:

1. The number of missing daily records is smaller than 100 , i.e. $0.25 \%$ of all records of the series.

2. Fewer than 100 records fail the quality assurance check set by the NCDC. 
Table 1 Information of the long-term daily mean temperature series used in the present study

\begin{tabular}{|c|c|c|c|c|c|c|}
\hline Id & Country & Station/NCDC id & Lat & Lon & Source or ref & For short \\
\hline 1 & Australia & ASN00086071 & -37.81 & 144.97 & NCDC & (1) Aus \\
\hline 2 & Canada & CA003031093 & 51.12 & -114.02 & $\mathrm{NCDC}$ & (2) $\mathrm{WCa}$ \\
\hline 3 & Canada & CA004016560 & 50.43 & -104.67 & NCDC & \\
\hline 4 & Canada & CA006105976 & 45.38 & -75.72 & NCDC & (3) $\mathrm{ECa}$ \\
\hline 5 & China & Shanghai & 31.4 & 121.45 & Yan et al. (2001) & (4) $\mathrm{ECh}$ \\
\hline 6 & Croatia & HR000142360 & 45.81 & 15.98 & NCDC & (5) $\mathrm{WEu}$ \\
\hline 7 & England & CET & 52.5 & -1.5 & Parker et al. (1992) & (6) CET \\
\hline 8 & Sweden & Stockholm & 59.35 & 18.07 & Moberg et al. (2002) & (7) $\mathrm{NEu}$ \\
\hline 9 & U.S. & USC00457938 & 47.62 & -117.52 & NCDC & (8) NWA \\
\hline 10 & U.S. & USC00244055 & 46.60 & -111.96 & NCDC & \\
\hline 11 & U.S. & USC00381549 & 32.78 & -79.93 & NCDC & (9) SEA \\
\hline
\end{tabular}

3. The time series is from a single source. Note that many temperature series at NCDC are blended by using data from different sources.

4. Only stations with good representativeness (in terms of correlation with nearby Caesar-gridded data for 1960-99, figures not shown) are chosen.

To avoid duplicate regional representativeness, the data of 2 stations in western Canada (ID number ' 2 ' and ' 3 ' in Table 1) are averaged into a regional series. The two station series have a correlation coefficient larger than 0.9. Another regional series is obtained by averaging stations ' 9 ' and ' 10 ' for northwestern America due to the same reason. Consequently, nine long-term daily temperature series were obtained (Table 1).

\subsubsection{Global monthly temperature 1901-2009}

The monthly global $0.5^{\circ}$ gridded land surface air temperature dataset (TS 3.1) for the period 1901-2009, developed at the Climatic Research Unit (CRU) (Jones and Harris 2008), is used.

\subsubsection{AMO index 1901-2009}

The AMO index used in this study is the de-trended (with the global mean sea surface temperature removed) and smoothed AMO index series for 1901-2009, developed by Trenberth and Shea (2006).

\subsubsection{Global monthly sea level pressure 1901-2009}

The monthly mean sea level pressure derived from the NOAA-CIRES twentieth century reanalysis version 2 dataset (Compo et al. 2011) are used for analyzing changes in atmospheric circulation in association with AMO.

\subsection{Methods}

Following Christidis et al. (2007), LGS is defined using a local temperature threshold to enable a global comparison. Three growing season indices are illustrated in Fig. 1: the mean threshold $\left(\mathrm{T}_{\mathrm{m}}\right)$, the start of the growing season (Ds) and the end of the growing season (De). $T_{m}$ is defined as the climatological annual mean temperature at a given location. For each year in Northern Hemisphere, Ds is the date when local temperature rises above $T_{m}$ in the spring and De is the date when local temperature falls below $\mathrm{T}_{\mathrm{m}}$ in the autumn (For convenience for global comparison, the seasonal cycle at a location in the Southern Hemisphere is shifted half a year forward). The period between Ds and De defines the local growing season length (GSL) for the year.

Due to high frequency weather fluctuations, Ds and De as defined supra may not be unique in a year, using raw daily temperatures. Various attempts have been applied to remove the noise and to uniquely determine Ds and De (e.g. Walther and Linderholm 2006; Christidis et al. 2007). A recently developed data-adaptive filter for nonlinear and non-stationary time-series analysis, the Ensemble Empirical Mode Decomposition (EEMD) method (Huang et al. 1998; Huang and Wu 2008; Wu and Huang 2009) has clear advantage for uniquely determining Ds and De with minimal distortion to the original data. The EEMD method allows to adaptively and temporally obtain the annual cycle and longer timescale component (ALC, the red line in Fig. 1). Detailed procedures to obtain the ALC can be found in Qian et al. (2009). Throughout this work, all the daily temperature series are decomposed using the EEMD method and Ds, De and the GSL are all calculated using the ALC component.

Following Wu et al. (2011), the EEMD method is also employed to adaptively decompose the LGS indices time series in order to obtain the multidecadal variability 
Fig. 1 An example of LGS indices for a particular year (year 1961) at a given location (Shanghai station): the start date of LGS (Ds), the end date of LGS (De), and the LGS length (GSL), which are defined using the mean temperature threshold (Tm) and raw daily temperatures ('Raw', black line), or using Tm and 'ALC' (the annual cycle and longer timescale component obtained using EEMD method, red line). Some low-filter methods used in previous growing season studies: 5-day running mean (green line), 10-day running mean (blue line), third-degree polynomial (pink line), for comparison with ALC

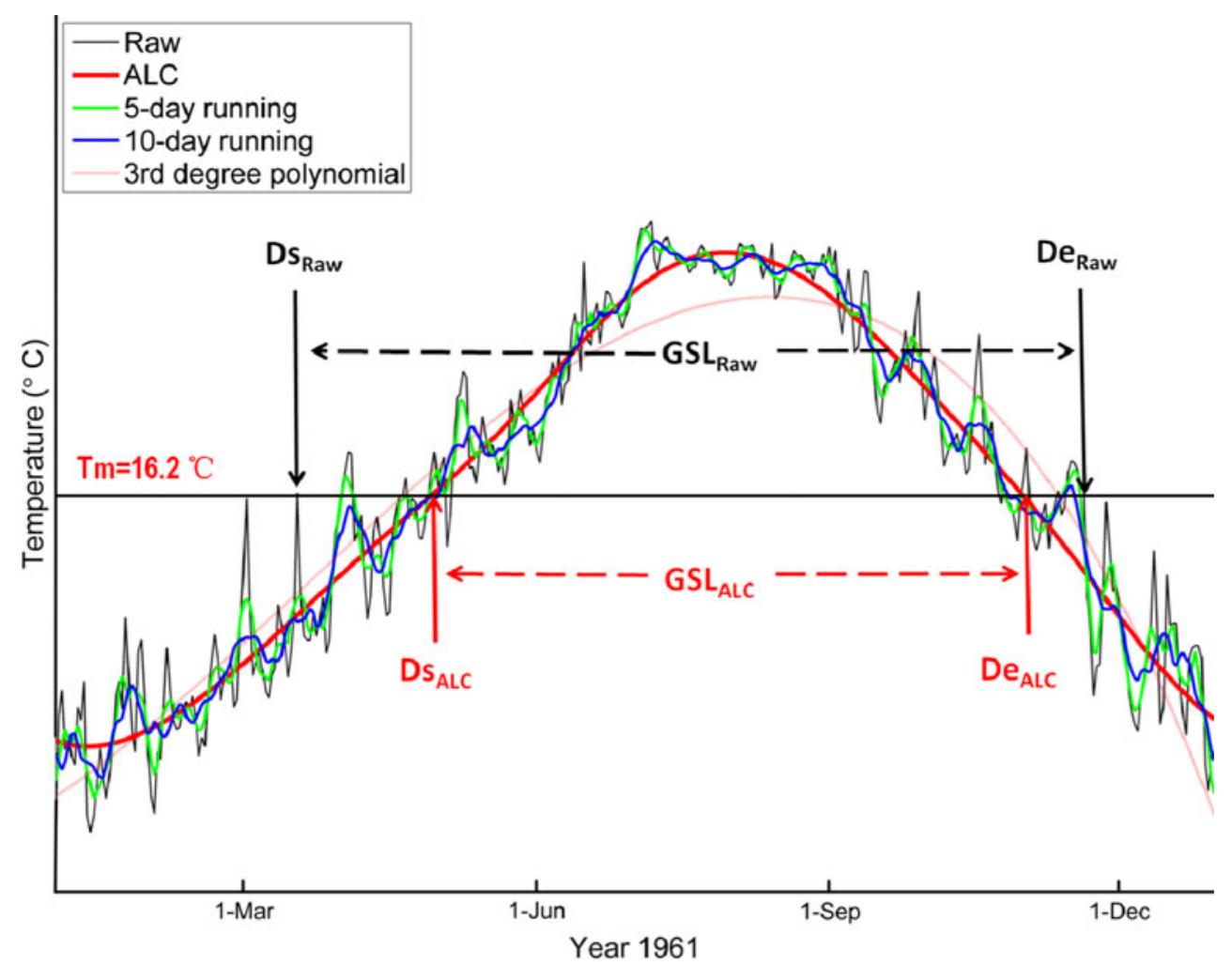

(MDV) component, defined as the second last component of EEMD, the last one being a secular trend. The sum of MDV and the secular trend can reproduce the main stepwise feature of global warming in the twentieth century (Wu et al. 2011). Details of calculating the MDV were given in $\mathrm{Wu}$ et al. (2011).

\section{Results}

\subsection{Changes in local growing season 1960-1999}

Figure 2 shows the linear trends for Ds (Fig. 2a), De (Fig. 2b) and the GSL (Fig. 2c) during the second half of the twentieth century using the global gridded dataset 1960-99 (Caesar et al. 2006). The analysis is similar to Christidis et al. (2007) except for the different methods used to determine Ds and De. Instead of using the third degree polynomial fit, the EEMD is employed to extract the annual cycle and longer timescale component. The first 10 years (1950-1959) are not included due to numerous missing data. Averaged over the observation areas, the Ds exhibits an advancing rate of about -0.89 days decade ${ }^{-1}$. In contrast, De shows a delaying rate of about 0.77 days decade $^{-1}$. Consequently, GSL has increased by a rate of 1.66 days decade ${ }^{-1}$. This is in agreement with findings of Christidis et al. (2007) who, using the same dataset for 1950-1999, found that GSL increased mainly due to an earlier start of the growing season. However, there are notable regional variations in changes in LGS indices. Especially in parts of North America and eastern Europe, it shows opposite but minor trends comparing with most of the other areas.

\subsection{Date-shift-rates for Ds and De of LGS}

Because of the relatively short period, changes revealed by Fig. 2 may contain natural climate variability on multidecadal timescales as noted by Kunkel et al. (2004). It would be highly desirable to extend the above analysis to a longer period. Pre-1950 daily temperature records are notoriously sparse (Alexander et al. 2006), but monthly mean data such as the CRU temperature series do exist. By analyzing the 1960-99 gridded daily temperature data, we find a good linear relationship between changes in the start date of local growing season $(\Delta \mathrm{Ds})$ and in April mean temperature $\left(\Delta \bar{T}_{\mathrm{Apr}}\right)$. A similar relationship also exists between $(\Delta \mathrm{De})$ and $\left(\Delta \bar{T}_{\text {Oct }}\right)$. This enables us to define two date-shift-rates $R_{d s}=\Delta D s / \Delta \bar{T}_{\mathrm{Apr}}$ and $R_{d e}=\Delta D e / \Delta \bar{T}_{\text {Oct. }}$ If $R_{d s}\left(R_{d e}\right)$ is known, $\Delta D s(\Delta D e)$ can then be estimated using $\Delta \bar{T}_{\text {Apr }}\left(\Delta \bar{T}_{\text {Oct }}\right)$.

Figure 3 shows the geographical distributions of $R_{d s}$ and $R_{d e}$ estimated using the global gridded daily temperature data. $R_{d s}$ ranges from -2 to -10 days ${ }^{\circ} \mathrm{C}^{-1}$ and $R_{d e}$ 1.7-8 days ${ }^{\circ} \mathrm{C}^{-1}$ in most of Northern Hemisphere, with roughly a latitudinal gradient over the continents and some 
Fig. 2 The linear trends for a Ds, b De and c GSL during the second half of the Twentieth century using the global gridded dataset 1960-99 (Caesar et al. 2006). Units: days decade ${ }^{-1}$. Warm colours indicate the trends associated with temperature increasing, i.e. trends of Ds advancing, De delaying, or GSL lengthening. Cool colours indicate the trends associated with temperature decreasing, i.e. trends of Ds delaying, De advancing, or GSL shortening. In each grid box where the trend (either negative or positive) is significant is marked with cross-hatching, based on Mann-Kendall test (Sneyers 1990)
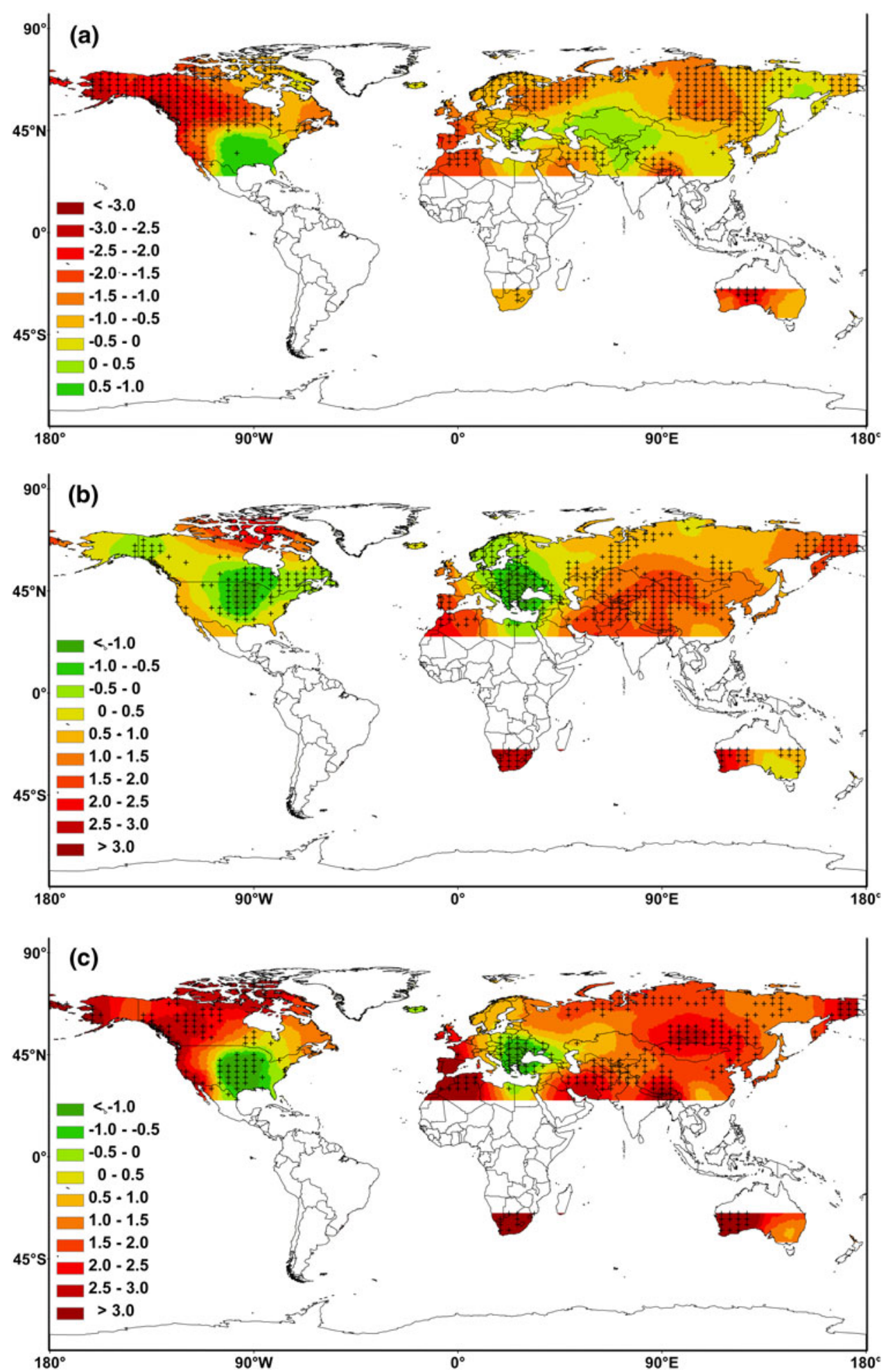

longitudinal gradient in coastal zones. It suggests that for the same magnitude of change in April (October) temperature, there should be a larger date shift of the start (end) of LGS in southern than northern Asia, southwestern than northeastern North America, and western than eastern Europe.
A key question is whether $R_{d s}$ and $R_{d e}$ are constant throughout the last century. If their variations are relatively small, one may attempt to use the monthly mean temperatures to estimate changes in Ds and De of the local growing season. The CRU dataset will then allow us to extend our analysis back to the beginning of the twentieth 
Fig. 3 The geographical distributions of $\mathbf{a} R_{d s}$ and $\mathbf{b} R_{d e}$ estimated using the global gridded daily temperature dataset 1960-99. Units: days ${ }^{\circ} \mathrm{C}^{-1}$. The correlation coefficients are larger than 0.90 at all locations, indicating good linear relationship between Ds and April temperature (or between De and October temperature). Marked with cross-hatching is a correlation coefficient larger than 0.95
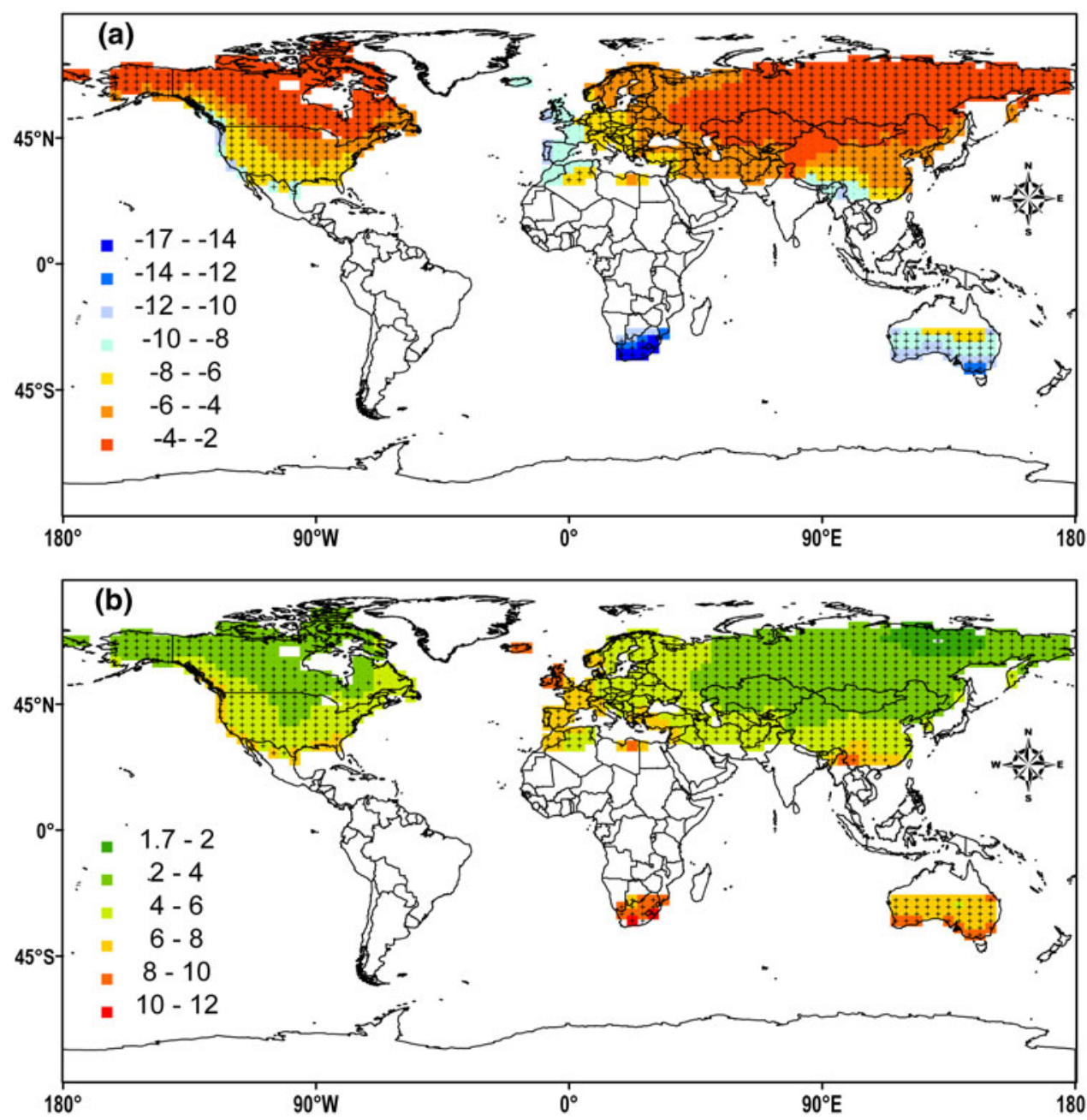

century. To assess the robustness of $R_{d s}$ and $R_{d e}$, we use the nine homogenized or strictly quality-controlled daily temperature series shown in Table 1. The time series at each location has continuous daily temperature records covering the period 1901-2008. $R_{d s}$ and $R_{d e}$ are calculated for each 40 -year-running period and the range of variations for each of the nine stations is shown in Fig. 4. It is clear that the error bars are very small so that we can regard $R_{d s}$ and $R_{d e}$ as constant. Therefore, it is feasible to estimate changes in local growing season from the beginning of the twentieth century by using $R_{d s}$ and $R_{d e}$ estimated from the latest datarich era and monthly mean temperature data for the whole period.

\subsection{Changes in local growing season 1901-2009}

Figure 5 shows changes in local growing season indices for the period 1901-2009. According to Fig. 5a, Ds exhibits advancing trends across almost all of the areas analyzed, i.e., warming in April has prevailed almost everywhere. This widespread warming (Ds advancing) pattern could be attributed to enhanced concentration of the atmospheric greenhouse gases (IPCC 2007). In contrast, De shows delaying trends in most areas (Fig. 5b). The exception is for parts of North America, with negative but minor trends, implying warming October in most areas but parts of North America. Averaged over the observation area, the Ds (De) shows an advancing (delaying) rate of about $-0.58(0.31)$ days decade ${ }^{-1}$. Then GSL has increased by a rate of 0.89 days decade $^{-1}$, mainly due to a significant earlier start of the LGS.

This is in agreement with findings of previous regional studies. For example, Linderholm et al. (2008) found a clear trend towards increasing growing season length (defined by $5{ }^{\circ} \mathrm{C}$ threshold) around the Baltic Sea for the twentieth century, with rates ranging from 0.9 to 3.4 days decade $^{-1}$, mainly due to significant changes in spring. Comparable results were also found over Canada (for the period 1900-1998, (Bonsal et al. 2001) and in the United States (for the period 1895-2000, Kunkel et al. 2004) by analyzing changes in the frost-free season length (defined by $0{ }^{\circ} \mathrm{C}$ threshold). In particular, Kunkel et al. (2004) 
Fig. 4 Distributions of dateshift-rate magnitudes for different 40-year-periods at nine locations: a $R_{d s}$, b $R_{d e}$."+" indicates the range of the 40-year-running date-shift-rate magnitudes throughout the period 1901-2008. The mean value is given for each series. Units: days ${ }^{\circ} \mathrm{C}^{-1}$

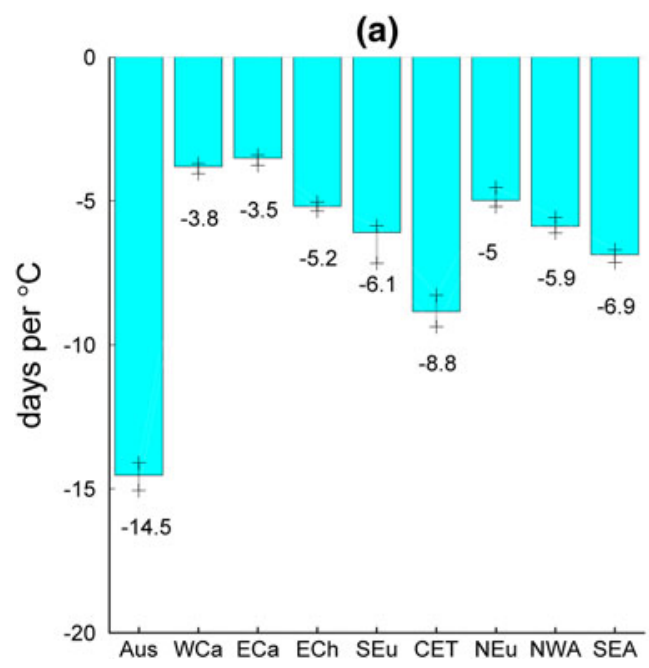

(b)

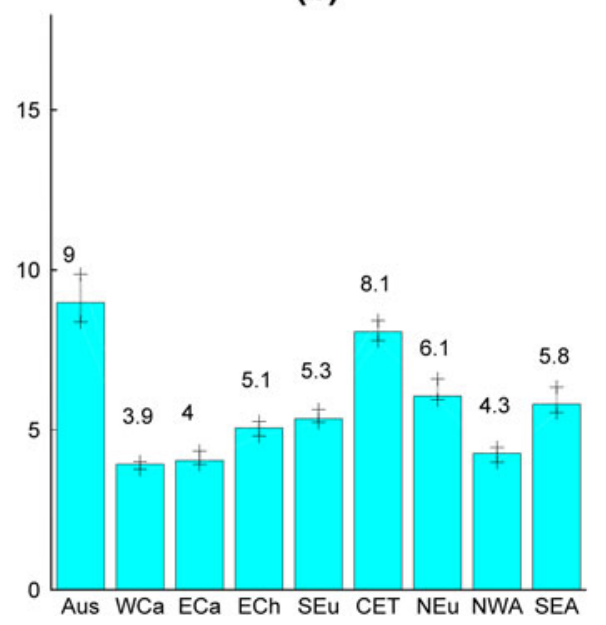

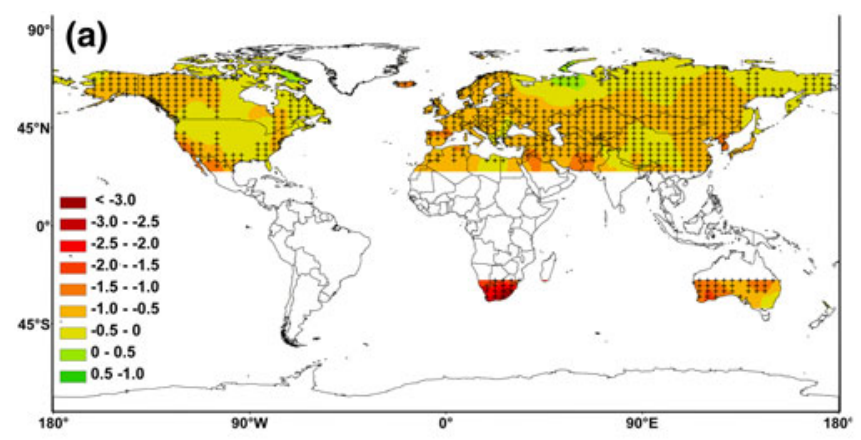
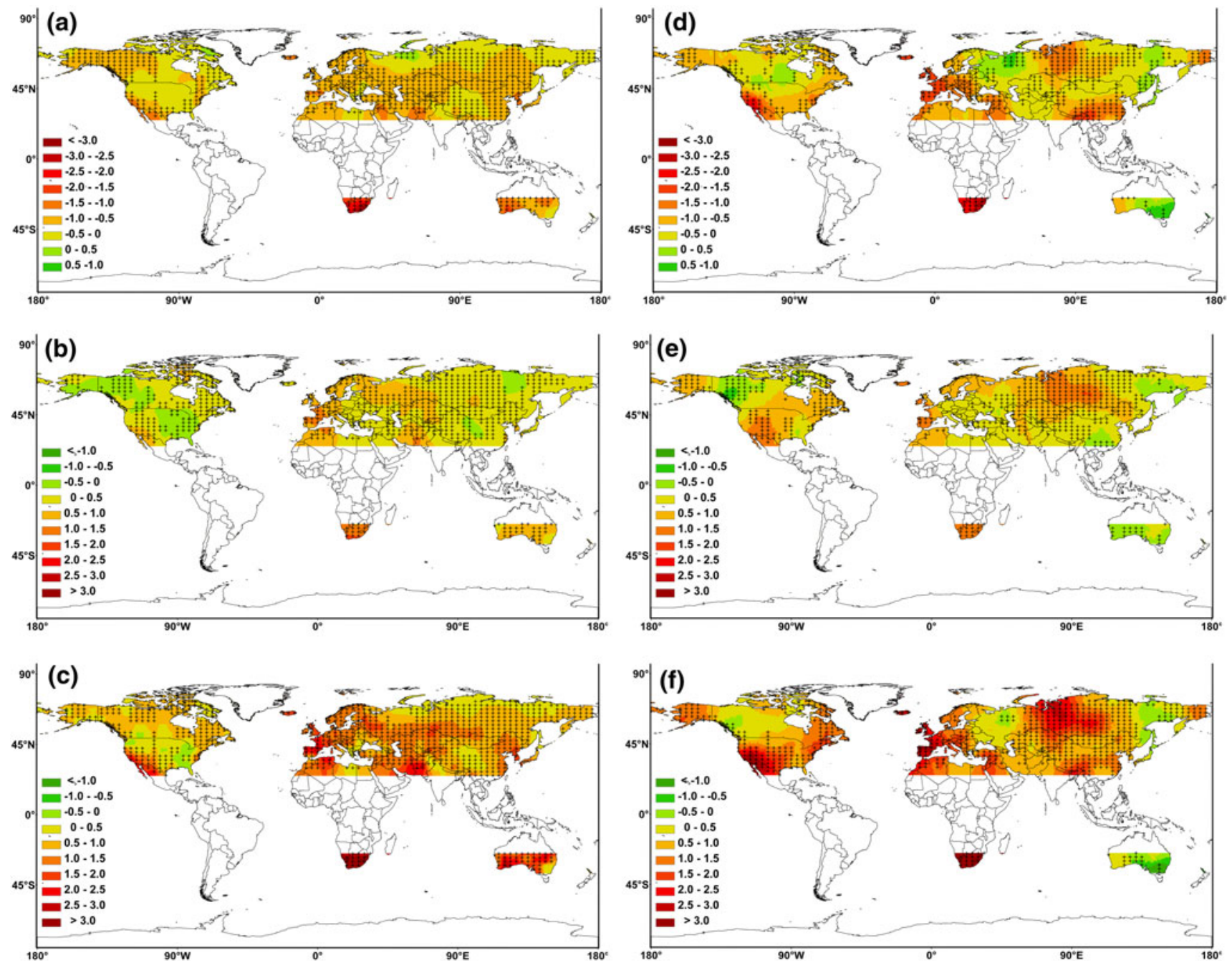

Fig. 5 Same as Fig. 2, but for linear trends of the LGS indices for 1901-2009 (left panel) and 1901-1960 (right panel) computed using the date-shift-rate $\left(R_{d s}\right.$ and $\left.R_{d e}\right)$ and the CRU T3.1 monthly

temperature (Jones and Harris 2008). a and $\mathbf{d}$ are for Ds, b and $\mathbf{e}$ are for De, $\mathbf{c}$ and $\mathbf{f}$ are for GSL. Units: days decade ${ }^{-1}$ 
pointed out that larger changes had occurred in the western U.S. (1.9 days decade ${ }^{-1}$ ) than in the eastern U.S. (0.3 days decade $\left.^{-1}\right)$, similar to the present results as expressed in Fig. 5c.

The present result demonstrates for the first time that LGS length has increased across Asia (0.8 days decade $\left.{ }^{-1}\right)$ since the beginning of the twentieth century, due to earlier shifts in Ds (0.53 days decade $\left.{ }^{-1}\right)$ and, to a less extent, delaying shifts in De $\left(0.27\right.$ days decade $\left.{ }^{-1}\right)$.

Comparing Fig. $5(\mathrm{a}-\mathrm{c})$ to Fig. 2, we find that the magnitudes are markedly smaller for the period 1901-2009 than 1960-99. Figure 5 (d, e, f) shows changes in LGS indices for the early half of the twentieth century 1901-1960 alone. Comparing Fig. 5d-f with Fig. 2, one finds that over some parts of the globe, especially in North America, eastern Europe, and Australia, the two figures show opposite trends. Over other areas, e.g. most of Asia, the magnitudes of the secular trends are different between the two periods. Previous regional studies (e.g. Carter 1998; Kunkel et al. 2004) also found that changes in LGS indices are not monotonic during the twentieth century. These suggest considerable MDV in the time series of the LGS indices.

\subsection{Relationship between MDV in LGS and AMO}

Analyses of global climate from measurements dating back to the nineteenth century show an 'Atlantic Multidecadal Oscillation' (AMO) as a leading large-scale pattern of multidecadal variability $(M D V)$ in surface temperature (Schlesinger and Ramankutty 1994; Trenberth and Shea 2006; Knight et al. 2005; 2006). Therefore, the following analysis of MDV of the LGS indices (i.e., April and October temperatures) is carried out with a comparative analysis of AMO index. Figure 6 illustrates the AMO index time series and the MDV component of monthly temperature. The correlation coefficients between the
MDV component of mean April (October) temperature series for the Northern Hemisphere and the AMO index series are 0.71 (0.78) for 1901-2009, indicating possible links between the AMO and MDV components of the LGS indices over the world.

The regression coefficients of the MDV components onto the AMO index are calculated and the global distributions are shown in Fig. 7. The regression pattern for October temperature (Fig. 7b) is similar to that for annual temperature (Fig. 9 in $\mathrm{Wu}$ et al. 2011), with positive coefficients almost everywhere in NH lands, i.e., in-phase relationships with the AMO in most land areas. In contrast, the April pattern (Fig. 7a) exhibits considerable regional differences-significant negative relationship exists in parts of North America, eastern Europe and western Asia, and minor parts of northeastern Asia including Japan. Figure 7c shows the global pattern of the April sea level pressure (SLP) difference (AMO warm phase composite minus cool phase composite). The Icelandic Low is deeper in AMO warm phase associated with stronger northwesterlies (and hence cooling) over continental North America while stronger southwesterlies (and hence warming) over western Europe. A positive SLP anomaly centered in eastern Europe indicates a westward shift of the Siberian high leading to a cooler eastern Europe and warmer Asia. A minor negative SLP departure center over and to the east of Japan may explain slightly cooler April in the upperstream region covering part of coastal northeastern Asia and Japan, similar to the situation for parts of North America. For October (Fig. 7d), there are hardly significant differences of SLP between the AMO positive and negative phases in the northern middle latitudes. Therefore, the response of October temperature appears quite straightforward to AMO throughout the Northern Hemisphere (Fig. 7b).

It is conceivable that the AMO plays an important role in regulating LGS indices within a time window of several
Fig. 6 Monthly mean temperature anomaly series averaged over the Northern Hemisphere during 1901-2009, for a April and b October. Raw data (golden line), MDV component (dark green line), ST (secular trend, the last component of EEMD output, red line) component, and the sum of MDV and ST (black line). 'AMO' (green) is the detrended and smoothed Atlantic Multi-decadal oscillation index series
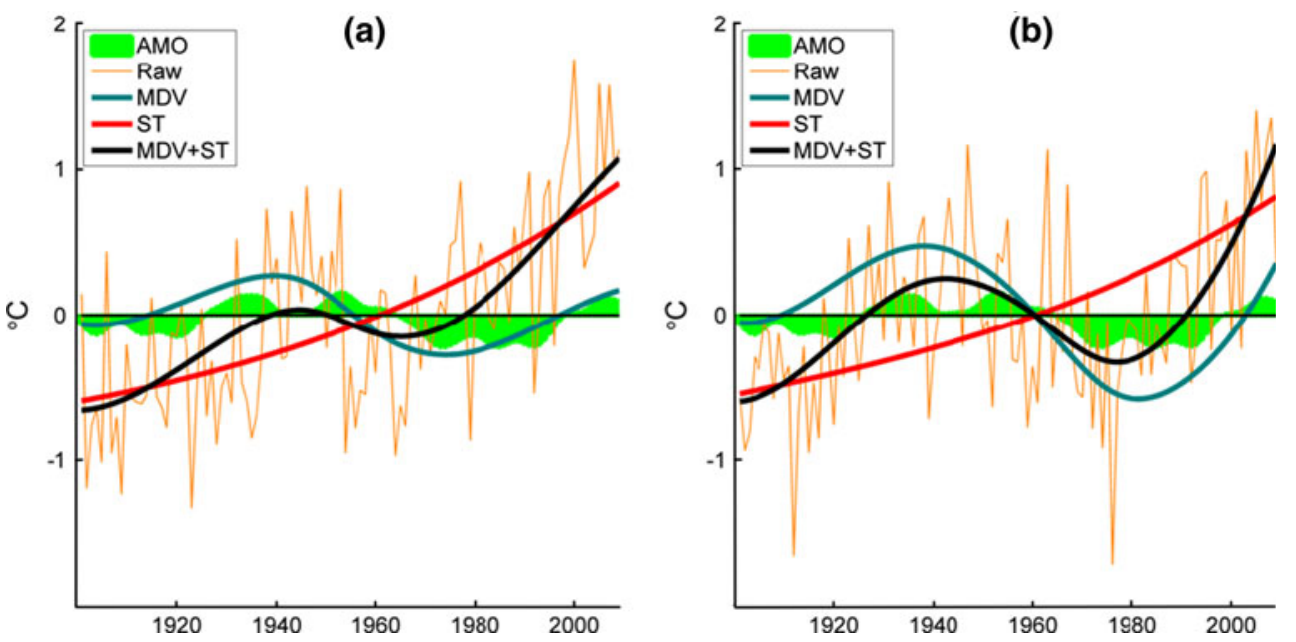


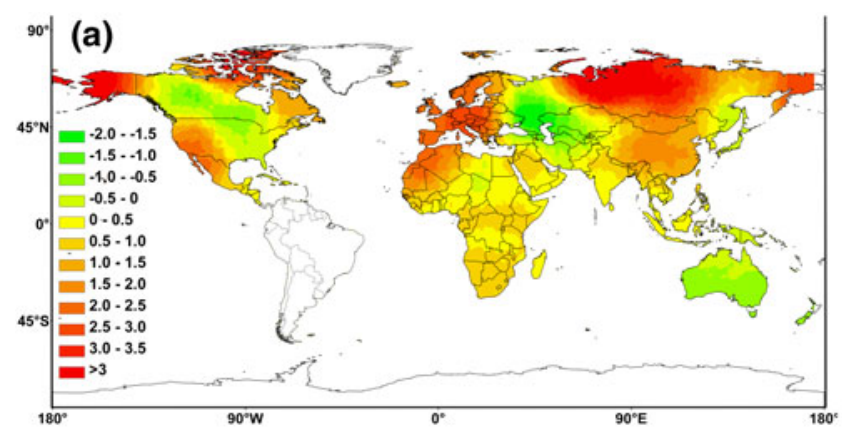

(c)

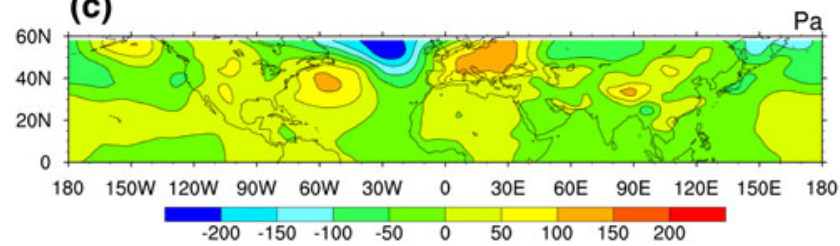

Fig. 7 Regressive coefficients linking AMO index series to MDV of a April and b October temperature time series for 1901-2009. The SLP departure fields between the AMO warm phase (1926-1965 and

decades, especially for the Northern Hemisphere. The MDV component extracted using EEMD does help to understand the underlying physics and is beneficial for the process based detection and attribution studies of changes in LGS. The phase change of AMO (Fig. 6) may have contributed to the lengthening of LGS over the past few decades. For example, during the AMO warming phase 1980-2009 (Fig. 6), averaged over the Northern Hemisphere, MDV accounts for about $6 \pm 2$ days of 11.4 days for LGS lengthening (a $53 \pm 18 \%$ contribution, the uncertainty being estimated based on the down sampling method developed by Wu et al. 2011).

According to $\mathrm{Wu}$ et al. (2011), i.e., MDV contributed up to one-third of the warming trend during the past 25 years. Obviously, MDV is more influential in the change of LGS. The main reason is that MDV is stronger in monthly (April or October) temperature time series than in annual temperature time series.

The present result implies some predictability of changes in LGS, as AMO is considered as a genuine quasiperiodic cycle of internal climate variability persisting for many centuries, and is predicted to move to a cooler phase over the next few decades (Knight et al. 2005; 2006). It is inferred that the lengthening trend of GSL observed in the past few decades may slow down in the future.

It is worth noting that other modes of natural variability, such as the Pacific Decadal Oscillation (labeled as PDO by Mantua et al. 1997) with climatic fingerprints mainly in the North Pacific/North American sector, could affect the MDV of temperature especially in the Pacific coastal areas (Mantua and Hare 2002). Changes in external

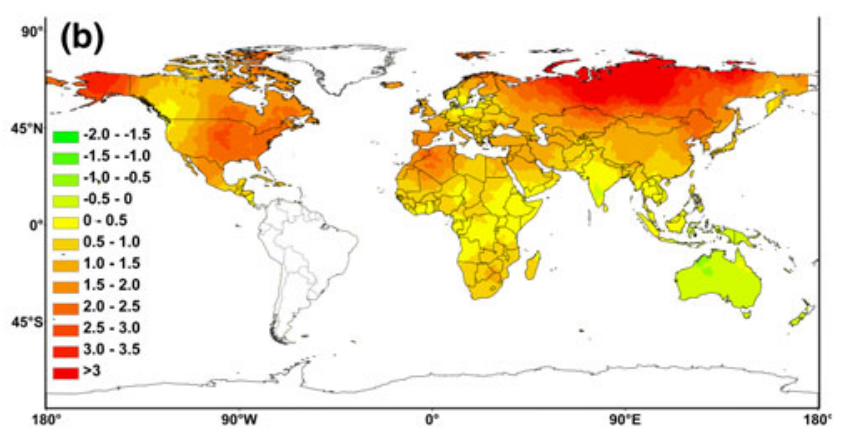

(d)

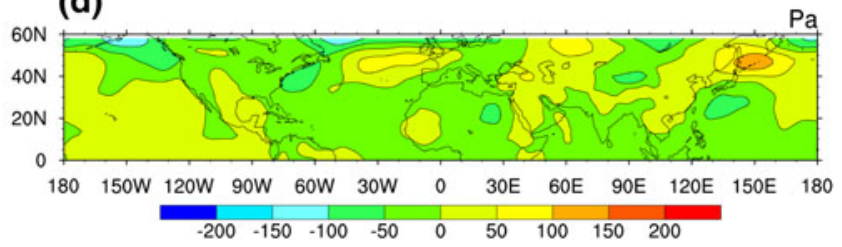

1999-2009) composite and cold phase (1901-1926 and 1965-1999) composite, for $\mathbf{c}$ April and $\mathbf{d}$ October. Units: $\mathrm{Pa}$

forcing, e.g., aerosols, could also affect the MDV of temperature in some regions for the last several decades (Mann and Emanuel 2006). A more comprehensive study of MDV in LGS should take into account of these factors.

\section{Summary}

Previous studies have shown a lengthening trend of LGS during the second half of the twentieth century. In this paper we have extended the investigation to the whole period of 1901-2009, based on CRU TS3.1 monthly temperature dataset and good linear relationships between changes in the two ends of LGS and in monthly mean temperature, i.e., an increase of $1{ }^{\circ} \mathrm{C}$ in the April (October) mean temperature corresponds to an advance (a delay) of 2-10 days (1.7-8 days) of the start (end) date for various locations over the world. Our results confirm previous findings of a lengthening trend in LGS, but with a smaller magnitude. Averaged over the observation area, the LGS length exhibits lengthening rate of about 0.89 days decade $^{-1}$, due mainly to an earlier start $(-0.58$ days dec$\left.\mathrm{ade}^{-1}\right)$. The difference between our estimates and previous studies is mainly because of multidecadal climate variability. It is suggested that AMO could have played a role in observed changes in LGS. In particular, MDV associated with AMO has enhanced the lengthening trend of LGS for most regions during the last three decades.

Acknowledgments This work was supported by grants CAS-SPRP XDA05090000; MOST-NBRPC 2012CB956200 and 2009CB421401. Peili Wu was supported by the Joint DECC/Defra Met Office Hadley 
Centre Climate Programme-DECC/Defra (GA01101). The two anonymous reviewers are gratefully acknowledged for their constructive reviews and helpful comments.

Open Access This article is distributed under the terms of the Creative Commons Attribution License which permits any use, distribution, and reproduction in any medium, provided the original author(s) and the source are credited.

\section{References}

ACIA (2004) Impacts of a warming Arctic: Arctic climate impact assessment. Cambridge University Press, UK $140 \mathrm{pp}$

Alexander LV, Zhang X, Peterson TC (2006) Global observed changes in daily climate extremes of temperature and precipitation. J Geophys Res 11:D05109. doi:10.1029/2005JD006290

Barnett TP, Adam JC, Lettenmaier DP (2005) Potential impacts of a warming climate on water availability in snow-dominated regions. Nature 438:303-309

Bonsal BR, Zhang X, Vincent LA, Hogg WD (2001) Characteristics of daily and extreme temperatures over Canada. J Clim 14:1959_ 1976

Brinkmann WAR (1979) Growing season length as an indicator of climatic variations? Clim Change 2:127-138

Caesar J, Alexander L, Vose R (2006) Large-scale changes in observed daily maximum and minimum temperatures: creation and analysis of a new gridded data set. J Geophys Res 111: D05101. doi:10.1029/2005JD006280

Carter TR (1998) Changes in the thermal growing season in Nordic countries during the past century and prospects for the future. Agric Food Sci Finland 7:161-179

Cayan DR, Kammerdiener SA, Dettinger MD, Caprio JM, Peterson DH (2001) Changes in the onset of spring in the western United States. Bull Am Meteorol Soc 3(82):399-415

Chmielewski FM, Müller A, Bruns E (2004) Climate changes and trends in phenology of fruit trees and field crops in Germany, 1961-2000. Agric For Meteor 121:69-78. doi:10.1016/S01681923(03)00161-8

Christidis N, Stott PA, Brown S, Karoly DJ, Caesar J (2007) Human contribution to the lengthening of the growing season during 1950-99. J Clim 20:5441-5454. doi:10.1175/2007JCLI1568.1

Compo GP, Whitaker JS, Sardeshmukh PD et al (2011) The twentieth century reanalysis project. Quarterly J Roy Meteorol Soc 137:128. doi:10.1002/qj.776

Cooter E, LeDuc S (1995) Recent frost date trends in the northeastern United States. Int J Climatol 15:65-75

Cotton PA (2003) Avian migration phenology and global climate change. Proc Natl Acad Sci USA 100:12219-12222

Crick HQP, Sparks TH (1999) Climate change related to egg-laying trends. Nature 399:423

Frich P, Alexander LV, Della-Marta P, Gleason B, Haylock M, Klein Tank AMG, Peterson T (2002) Observed coherent changes in climatic extremes during the second half of the twentieth century. Clim Res 19:193-212

Goulden ML, Munger JW, Fan SM, Daube BC, Wofsy SC (1996) Exchange of carbon dioxide by a deciduous forest: response to interannual climate variability. Science 271:1576-1578

Groisman PY, Knight RW, Karl TR, Easterling DR, Sun B, Lawrimore JH (2004) Contemporary changes of the hydrological cycle over the contiguous United States: trends derived from in situ observations. J Hydrometeor 5:64-85

Huang NE, Wu Z (2008) A review on Hilbert-Huang transform: method and its applications to geophysical studies. Rev Geophys 46: RG2006. doi:10.1029/2007RG000228
Huang NE, Shen Z, Long SR, Wu MC, Shih EH, Zheng Q, Tung CC, Liu HH (1998) The empirical mode decomposition and the Hilbert spectrum for nonlinear and nonstationary time series analysis. Proc Roy Soc London 454 A:903-995

IPCC (2007) Climate change 2007: Synthesis report. Contribution of working groups I, II and III to the fourth assessment report of the intergovernmental panel on climate change. Pachauri RK Reisinger A, (eds) (IPCC) Available at: http://www.ipcc.ch/ publications_and_data/ar4/syr/en/contents.html

Jones PD, Briffa KR (1995) Growing season temperatures over the former Soviet Union. Int J Climatol 151:943-959

Jones P, Harris I (2008), University of East Anglia Climate Research Unit (CRU), CRU Time Series (TS) High Resolution Gridded Datasets [Internet]. NCAS British Atmospheric Data Centre. Available from: http://badc.nerc.ac.uk/view/badc.nerc.ac.uk_ ATOM_dataent_1256223773328276. My data are the ones available in the archive at this particular point in time 1 Jun 2011

Jones GV, White MA, Cooper OR, Storchmann K (2005) Climate change and global wine quality. Clim Change 73:319-343

Keeling CD, Chin JFS, Whorf TP (1996) Increased activity of northern vegetation inferred from atmospheric $\mathrm{CO} 2$ measurements. Nature 382:146-149

Knight JR, Allan RJ, Folland CK, Vellinga M, Mann ME (2005) A signature of persistent natural thermohaline circulation cycles in observed climate. Geophys Res Lett 32:L20708. doi:10.1029/ 2005GL024233

Knight JR, Folland CK, Scaife AA (2006) Climate impacts of the Atlantic multidecadal oscillation. Geophys Res Lett 33:L17706. doi:10.1029/2006GL026242

Kunkel KE, Easterling DR, Hubbard K, Redmond K (2004) Temporal variations in frost-free season in the United States: 1895-2000. Geophys Res Lett 31:L03201. doi:10.1029/2003GL018624

Linderholm HW (2006) Growing season changes in the last century. Agric Forest Meteorol 137:1-14. doi:10.1016/j.agrformet.2006. 03.006

Linderholm HW, Walther A, Chen D (2008) Twentieth-century trends in the thermal growing season in the Greater Baltic area. Clim Change 87:405-419. doi:10.1007/s10584-007-9327-3

Mann ME, Emanuel KA (2006) Atlantic hurricane trends linked to climate change. EOS 87:233-244

Mantua NJ, Hare SR (2002) The Pacific decadal oscillation. J Oceanogr 58:35-44

Mantua NJ, Hare SR, Zhang Y (1997) A pacific interdecadal climate oscillation with impacts on salmon production. Bull Amer Meteor Soc 78:1069-1079

Matsumoto K, Ohta T, Irasawa M, Nakamura T (2003) Climate change and extension of the Ginkgo biloba L. growing season in Japan. Global Change Biol 9:1634-1642

Moberg A, Bergstrom H, Ruiz Krigsman J, Svanered O (2002) Daily air temperature and pressure series for Stockholm (1756-1998). Clim Change 53:171-212

Myneni RB, Keeling CD, Tucker CJ, Asrar G, Nemani RR (1997) Increased plant growth in the northern high latitudes from 1981 to 1991. Nature 386:698-702

Nemani RR, White MA, Cayan DR, Jones GV, Running SW, Coughlan JC, Peterson DL (2001) Asymmetric warming over coastal California and its impact on the premium wine industry. Climate Res 19:25-34

Parker DE, Legg TP, Folland CK (1992) A new daily central England temperature series 1772-1991. Int J Climatol 12:317-342

Parmesan C, Yohe G (2003) A globally coherent fingerprint of climate change impacts across natural systems. Nature 421: $37-42$

Peng S, Huang J, Sheehy JE et al (2004) Rice yields decline with higher night temperature from global warming. Porc Natl Acad Sci USA 101:9971-9975 
Peterson BJ, Holmes RM, McClelland JW, Vorosmarty CJ, Lammers RB, Shiklomanov AI, Shiklomanov IA, Rahmstorf S (2002) Increasing river discharge to the Arctic Ocean. Science 298: 2171-2173

Qian C, Fu CB, Wu ZH, Yan ZW (2009) On the secular change of spring onset at Stockholm. Geophys Res Lett 36:L12706. doi: 10.1029/2009GL038617

Root TL, Price JT, Hall KR, Schneider SH, Rosenzweig C, Pounds JA (2003) Fingerprints of global warming on wild animals and plants. Nature 421:57-60

Roy DB, Sparks TH (2000) Phenology of British butterflies and climate change. Global Change Biol 6:407-416

Schlesinger ME, Ramankutty N (1994) An oscillation in the global climate system of period 65-70 years. Nature 367:723-726

Sneyers R (1990) On the statistical analysis of series of observations. WMO Technical Note No. 143, Secretariat of the World Meteorological Organization, Geneva, Switzerland

Song YL, Linderholm HW, Chen D, Walther A (2010) Trends of the thermal growing season in China, 1951-2007. Int J Climatol 30:33-43. doi:10.1002/joc. 1868

Trenberth KE, Shea DJ (2006) Atlantic hurricanes and natural variability in 2005. Geophys Res Lett 33:L12704. doi:10.1029/ 2006GL026894
Walther A, Linderholm HW (2006) A comparison of growing season indices for the Greater Baltic Area. Int J Biometeorol 51:107118. doi:10.1007/s00484-006-0048-5

White MA, Running SW, Thornton PE (1999) The impact of growing-season length variability on carbon assimilation and evapotranspiration over 88 years in the eastern US deciduous forest. Int J Biometeorol 42:139-145

Wu Z, Huang NE (2009) Ensemble empirical mode decomposition: a noise-assisted data analysis method. Adv Adapt Data Anal 1: $1-41$

Wu Z, Huang NE, Wallace JM, Smoliak BV, Chen X (2011) On the time-varying trend in global-mean surface temperature. Clim Dyn 37:759-773. doi:10.1007/s00382-011-1128-8

Yan Z, Yang C, Jones PD (2001) Influence of Inhomogeneity on the estimation of mean and extreme temperature trends in Beijing and Shanghai. Adv Atmos Sci 18(3):309-322

Yang DQ, Kane DL, Hinzman LD, Zhang X, Zhang T, Ye H (2002) Siberian Lena River hydrologic regime and recent change. J Geophys Res 107:4694. doi:10.1029/2002JD002542 